\title{
Fatal hemorrhage from a gastroaortic fistula secondary to gastric ulceration associated with Nissen fundoplication and nonsteroidal anti-inflammatory drug use
}

\author{
Marsoh Manduch MD MSc${ }^{1}$, John P Rossiter MB BCh PhD ${ }^{1}$, William T Depew MD², \\ C Dale Mercer $\mathrm{MD}^{3}$, David J Hurlbut $\mathrm{MD}^{1}$
}

\begin{abstract}
M Manduch, JP Rossiter, WT Depew, CD Mercer, DJ Hurlbut. Fatal hemorrhage from a gastroaortic fistula secondary to gastric ulceration associated with Nissen fundoplication and nonsteroidal anti-inflammatory drug use. Can J Gastroenterol 2008;22(3):299-302.
\end{abstract}

Une hémorragie fatale causée par une fistule aortogastrique secondaire à un ulcère gastrique associé à une fundoplicature de Nissen et à la prise d'anti-inflammatoires non stéroïdiens
Acute gastrointestinal hemorrhage from a gastroaortic fistula in the gastric fundoplication pouch is a rare complication of Nissen fundoplication. The present case reports a gastroaortic fistula secondary to gastric ulceration associated with prior Nissen fundoplication and nonsteroidal anti-inflammatory drug use. A 55-year-old man presented with massive hematemesis and died of exsanguination during emergency laparotomy. Recognition of factors that predispose a patient to gastric ulceration after fundoplication, including nonsteroidal anti-inflammatory drug use, is critical to arouse the high index of suspicion required to diagnose and manage this lifethreatening complication.

\begin{abstract}
L'hémorragie gastro-intestinale aiguë causée par une fistule aortogastrique de la cavité de fundoplicature gastrique est une complication rare de la fundoplicature de Nissen. Le présent cas fait état d'une fistule aortogastrique secondaire à un ulcère gastrique associé à une fundoplicature de Nissen antérieure et à la prise d'anti-inflammatoires non stéroïdiens. Un homme de 55 ans a présenté une hématémèse massive et est mort d'exsanguination pendant une laparotomie d'urgence. Il est essentiel de connaître les facteurs qui prédisposent un patient à un ulcère gastrique après une fundoplicature, y compris la prise d'anti-inflammatoires non stéroïdiens, afin de susciter le fort indice de présomption nécessaire pour diagnostiquer et prendre en charge cette complication qui constitue un danger de mort.
\end{abstract}

Key Words: Gastric ulceration; Gastroaortic fistula; Nissen fundoplication

Tissen fundoplication is a common and effective surgical 1 procedure for gastroesophageal reflux disease refractory to medical therapy. Rare complications of this procedure include gastric ulceration leading to formation of a gastroaortic fistula (1-4). This may result in severe, potentially life-threatening, upper gastrointestinal hemorrhage. The present report documents the formation of a gastroaortic fistula likely secondary to nonsteroidal anti-inflammatory drug (NSAID)-induced gastric ulceration four years after Nissen fundoplication for gastroesophageal reflux disease.

\section{CASE PRESENTATION}

The patient was a 55-year-old man who presented to the emergency department at Kingston General Hospital (Kingston, Ontario) with unstable gastrointestinal bleeding. He had been found obtunded on the floor of his home with approximately $2 \mathrm{~L}$ of blood in the surrounding area. His wife gave an account of his medical history, which included complaints of epigastric pain and cramping for two days before the event. His medical history was significant for severe reflux esophagitis that had failed antireflux medical therapy. He had undergone a Nissen fundoplication four years earlier for treatment of esophagitis and gastroesophageal reflux. His symptoms had resolved after surgery. He was taking indomethacin and morphine sulfate for chronic back and pleuritic chest pain for 10 months before admission. The indomethacin dosage had been recently increased to $75 \mathrm{mg}$ three times per day. On arrival at the hospital, he was in severe hypovolemic shock, with a systolic blood pressure of $60 \mathrm{mmHg}$. His initial laboratory investigations showed a hemoglobin level of $83 \mathrm{~g} / \mathrm{L}$, leukocytes $15.2 \times 10^{9} / \mathrm{L}$, platelets $199 \times 10^{9} / \mathrm{L}$ and an international normalized ratio of 1.5. An NSAID-induced gastric ulceration was suspected initially. The patient was aggressively resuscitated with nine units of packed red blood cells, five units of platelets and five units of fresh frozen plasma. He was intubated and an urgent upper endoscopy was performed, which demonstrated a large amount of fresh and clotted blood in the stomach. A specific site of hemorrhage was not identified. However, the proximal one-half of the stomach could not be adequately seen because of a large obstructing blood clot. A subsequent visceral angiogram including the celiac and superior mesenteric arteries also failed to show any evidence of a bleeding source. Due to ongoing bleeding, an emergency laparotomy was performed in an attempt to control the active hemorrhage. It was found intraoperatively that the stomach had ruptured posteriorly. An anterior gastrotomy was performed, which revealed massive bleeding originating in the proximal one-half of the stomach. A left lower anterior thoracotomy was performed,

\footnotetext{
${ }^{1}$ Department of Pathology and Molecular Medicine; ${ }^{2}$ Department of Medicine (Gastroenterology); ${ }^{3}$ Department of Surgery, Kingston General Hospital, Queen's University, Kingston, Ontario

Correspondence: Dr David J Hurlbut, Department of Pathology and Molecular Medicine, Kingston General Hospital, 76 Stuart Street, Kingston, Ontario K7L 2V7. Telephone 613-549-6666 ext 6035, fax 613-548-6076, e-mail hurlbutd@kgh.kari.net

Received for publication July 30, 2007. Accepted October 16, 2007
} 


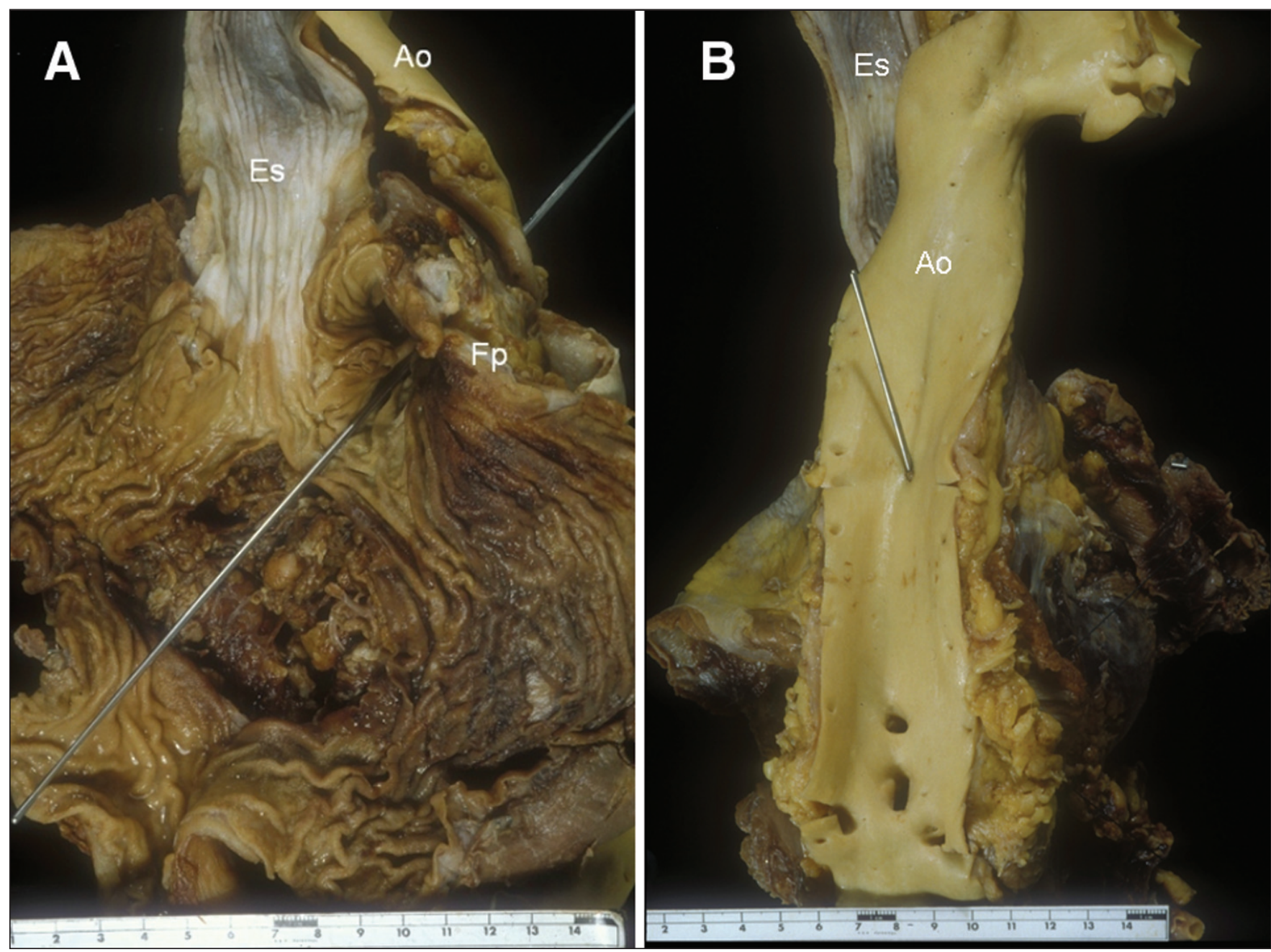

Figure 1) A Anterior view of the postmortem specimen showing the luminal aspect of the gastroesophageal junction, fundic wrap and gastric fundus. B Posterior view of the specimen showing the lumen of the aorta. The probe demonstrates the gastroaortic fistula tract. Ao Aorta; Es Esophagus; Fp Fundoplication wrap

and the aorta was occluded using digital palpation manipulation with good proximal control of the bleeding. However, the patient's ventricular rhythm decompensated into ventricular fibrillation and he expired on the operating table.

The postmortem examination showed evidence of recent emergency laparotomy with gastrotomy. There was a $9.5 \mathrm{~cm}$ linear incision along the anterior wall of the body of the stomach. The gastric antrum contained only a few millilitres of blood, whereas the duodenum, jejunum and ileum were filled with a large amount of clotted blood. Evidence of remote Nissen fundoplication surgery was noted. A pouch-like component of the fundoplication wrap, measuring $5 \mathrm{~cm} \times 3.5 \mathrm{~cm}$ $\times 3.5 \mathrm{~cm}$ in greatest dimensions, was identified situated on the left side of the esophagus. The posterior surface of this pouch was densely adhered to the anterior surface of the lower thoracic aorta. A $5 \mathrm{~cm} \times 2 \mathrm{~cm}$ zone of mucosal ulceration was present on the posterolateral wall of the fundoplication pouch. A $2 \mathrm{~mm}$ perforation overlying a gastroaortic fistula was noted, involving the anterior wall of the lower thoracic portion of the aorta, secondary to the chronic gastric ulcer in the fundoplication (Figures 1 and 2). Aside from the Nissen fundoplication, the esophagus was unremarkable with no evidence of esophagitis. The aorta showed only minimal atherosclerosis.
Histological sections from the area of the fistulous tract showed erosion of the gastric mucosa with transmural ulceration. The posterior surface of the stomach was directly apposed to the aorta by fibrosis and chronic inflammation. Giemsastained sections of the gastric antrum and fundoplication were negative for Helicobacter pylori organisms.

\section{DISCUSSION}

Aortoenteric fistulas develop uncommonly as a result of either aortic or gastrointestinal pathology. Aortic abnormalities that may predispose a patient to fistula formation include aortic aneurysms, atherosclerotic disease, infections or postaortic vascular graft placement (5-7). Gastrointestinal pathology includes irradiation for malignancy, peptic ulcer disease, foreign bodies and ingestion of corrosive materials (8). A gastroaortic fistula can occasionally form secondary to gastric ulceration after Nissen fundoplication for gastroesophageal reflux disease. This complication is very rare and has been described in only a handful of cases $(1-4,9)$.

The most common causes of gastric ulceration include $H$ pylori and NSAIDs $(10,11)$. However, these etiologies have not been directly implicated in the post-Nissen fundoplication gastroaortic fistula patient population. Instead, the cause of 

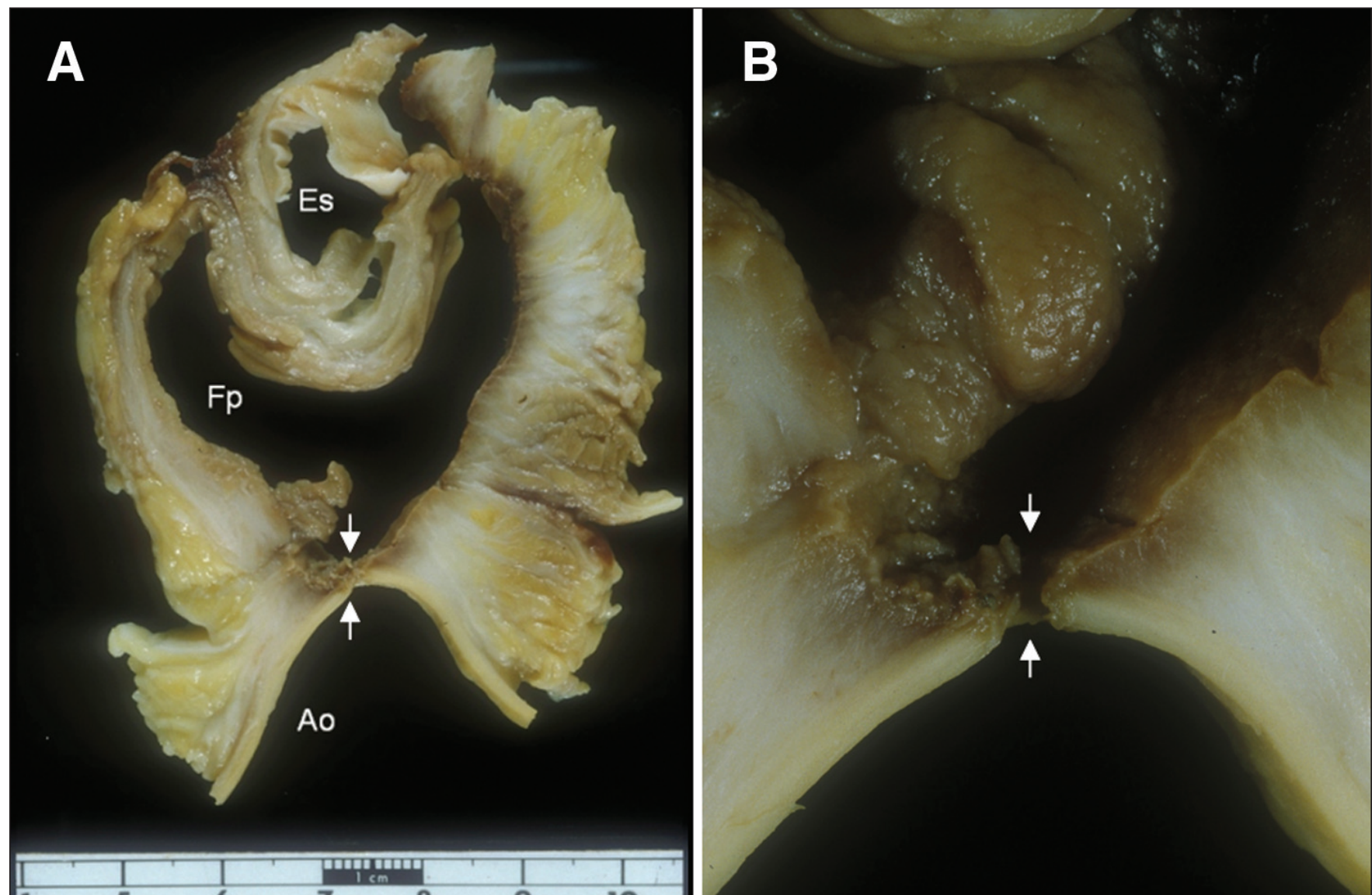

Figure 2) A Cross-section through the fundic wrap. Note the close juxtaposition of the posterior aspect of the fundic wrap and the aorta at the site of the gastroaortic fistula (arrows). B Close up view of the fistula tract between the fundoplication wrap (top arrow) and the thoracic aorta (bottom arrow). Ao Aorta; Es Esophagus; Fp Fundoplication wrap

ulceration after Nissen fundoplication has been hypothesized to be mechanical in nature. Possible mechanisms include surgical trauma, delayed gastric emptying due to vagal injury, hypergastrinemia, suture irritation from the wrap, and gastric wall ischemia due to ligation of short gastric vessels. Over time, these factors may result in gastric ischemia leading to ulceration, which given the close proximity of the aorta and the stomach due to the surgical fundoplication procedure, gives rise to the subsequent development of a fistula (12). In addition to the above potential mechanical factors, we believe the prolonged use of NSAIDs in the present case likely contributed to gastric ulceration of the fundoplication, resulting in fistula formation.

Due to the rarity of aortogastroenteric fistulas, the diagnosis is frequently missed or made too late for surgical correction, often resulting in a fatal outcome (4). A great proportion of the few cases of primary aortoenteric fistulas first presented with 'herald bleeding,' attributed to spasms of the intestinal musculature that temporarily close the fistula and stop the initial bleeding. A review of relevant literature by Wasvary et al (4) identified 10 of 14 cases that presented with a herald bleed before a massive upper gastrointestinal hemorrhage. The diagnostic triad described by Lewis and Allan (13) may be helpful in establishing the clinical diagnosis. It includes a history of hemorrhage with no obvious source, a pulsatile abdominal mass and recurrent cardiovascular collapse. Any previous gastroesophageal surgery or distortion of the gastrointestinal anatomy is also highly suggestive of a potential primary aortogastroenteric fistula in these circumstances. As demonstrated by our case, a history of Nissen fundoplication, especially with a background of NSAID use, should serve to bring this rare complication to the forefront of the differential diagnosis.

Regrettably, the diagnostic sensitivity of computed tomography, and even arteriography or gastroduodenoscopy is low (14). Definite diagnosis is often made only during operative exploration or at autopsy (4). In the present case, both the upper gastrointestinal endoscopy and the selective visceral angiogram did not identify the source of the hemorrhage. Specifically, the gastroaortic fistula was not seen endoscopically, likely due to its location within the fundoplication wrap itself. In this case, angiographic examination of the aorta proximal to the celiac artery was not undertaken. Accordingly, the fistula site was not included in the study. Whether aortography proximal to the celiac artery would have identified the fistula is speculative, but it is worth considering in similar circumstances.

\section{SUMMARY}

Gastroaortic fistula is a rare, but potentially life-threatening, complication after Nissen fundoplication. Recognition of ulcerogenic factors, including NSAID use, that predispose a postfundoplication patient to gastric ulceration is critical to arouse the high index of suspicion required to diagnose and manage this rare complication. 


\section{Manduch et al}

\section{REFERENCES}

1. Agrez MV, Ferguson NW. Aorto-gastric fistula following Nissen fundoplication. Aust N Z J Surg 1990;60:823-5.

2. Harwood JT, Moore JB, Moore E. Gastro aortic fistula: Complication following Thal patch and Nissen fundoplication. Colo Med 1980;77:300-2.

3. Kougias P, Baltazar U, Battle WJ, Rush DS, Browder IW, Katras T. Primary aortogastric fistula after Nissen fundoplication: A case report and review of pertinent literature. Vasc Endovascular Surg 2003;37:135-9.

4. Wasvary H, Wease G, Bierema T, Glover J. Gastro-aortic fistula: An uncommon complication of Nissen fundoplication. Am Surg 1997;63:455-8.

5. Busuttil RW, Rees W, Baker JD, Wilson SE. Pathogenesis of aortoduodenal fistula: Experimental and clinical correlates. Surgery 1979;85:1-13.

6. Elliott JP Jr, Smith RF, Szilagyi DE. Proceedings:

Aortoenteric and paraprosthetic-enteric fistulas. Problems of diagnosis and management. Arch Surg 1974; 108:479-90.

7. Levy MJ, Todd DB, Lillehei CW, Varco RL. Aorticointestinal fistulas following surgery of the aorta. Surg Gynecol Obstet 1965;120:992-6.
8. Pickhardt PJ, Bhalla S, Balfe DM. Acquired gastrointestinal fistulas: Classification, etiologies, and imaging evaluation. Radiology 2002;224:9-23.

9. Pianka JD, Smith CD, Waring JP. Acute upper gastrointestinal hemorrhage from an ulcer on a Nissen fundoplication. Am J Gastroenterol 2000;95:315-6.

10. Hamid S, Yakoob J, Jafri W, Islam S, Abid S, Islam M. Frequency of NSAID induced peptic ulcer disease. J Pak Med Assoc 2006;56:218-22.

11. Zapata-Colindres JC, Zepeda-Gómez S, Montaño-Loza A, Vázquez-Ballesteros E, de Jesús Villalobos J, Valdovinos-Andraca F. The association of Helicobacter pylori infection and nonsteroidal anti-inflammatory drugs in peptic ulcer disease. Can J Gastroenterol 2006;20:277-80.

12. Schauer PR, Meyers WC, Eubanks S, Norem RF, Franklin M, Pappas TN. Mechanisms of gastric and esophageal perforations during laparoscopic Nissen fundoplication. Ann Surg 1996;223:43-52.

13. Lewis RT, Allan CM. Spontaneous aortoduodenal fistula: Successful treatment by extra-anatomic vascular bypass. Can J Surg 1979;22:234-6.

14. Dossa CD, Pipinos II, Shepard AD, Ernst CB. Primary aortoenteric fistula: Part 1. Ann Vasc Surg 1994;8:113-20. 


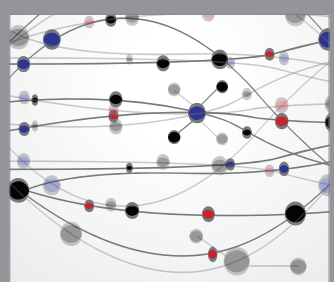

The Scientific World Journal
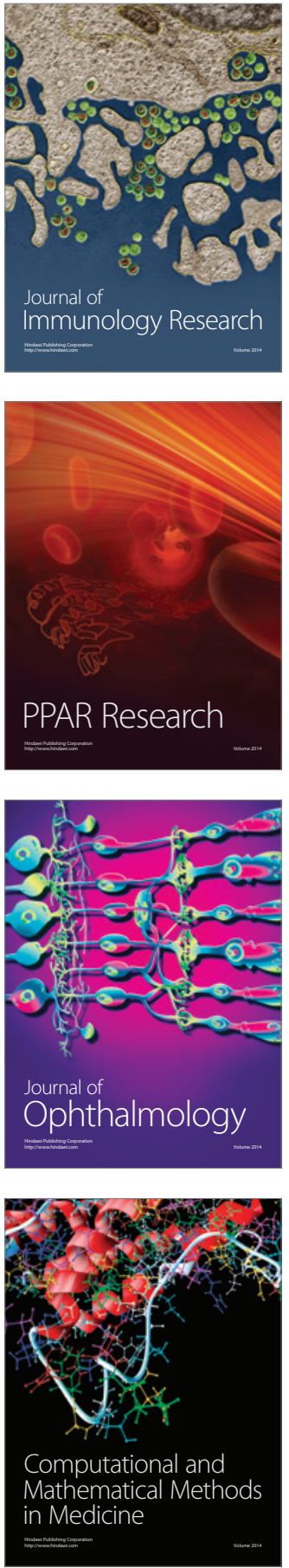

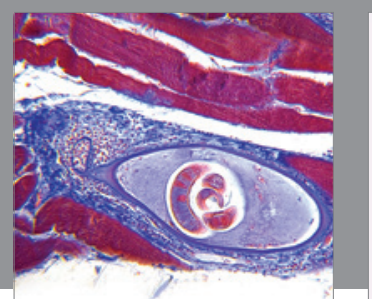

Gastroenterology Research and Practice

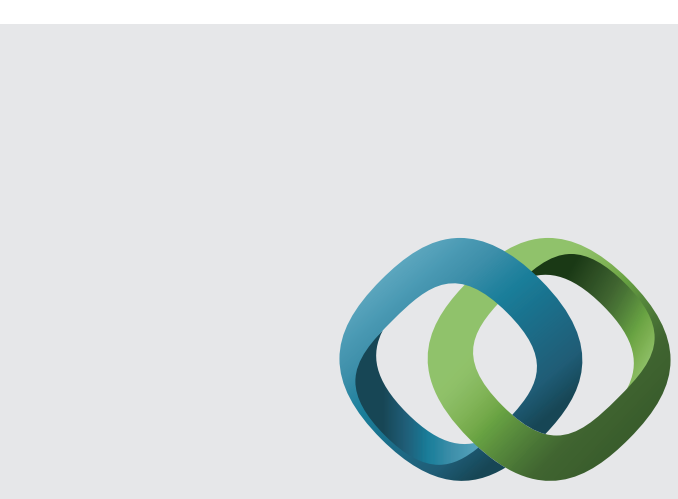

\section{Hindawi}

Submit your manuscripts at

http://www.hindawi.com
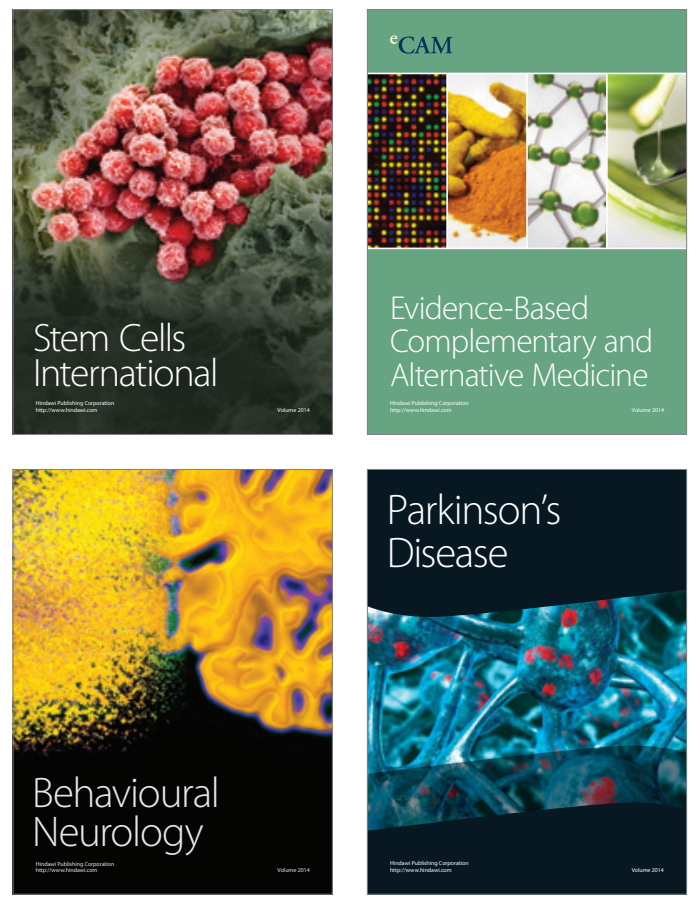
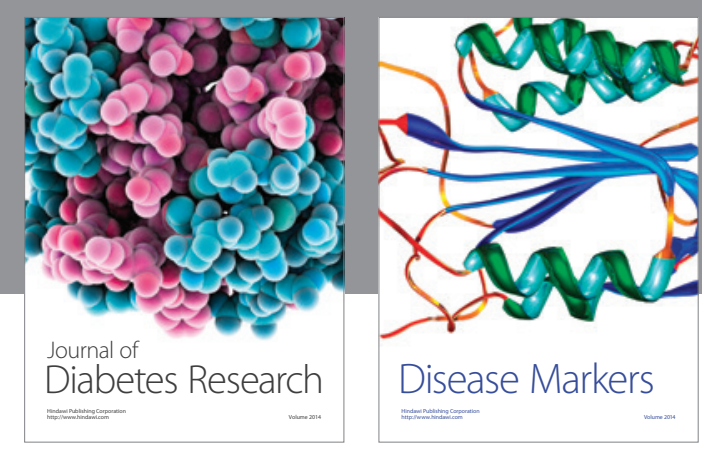

Disease Markers
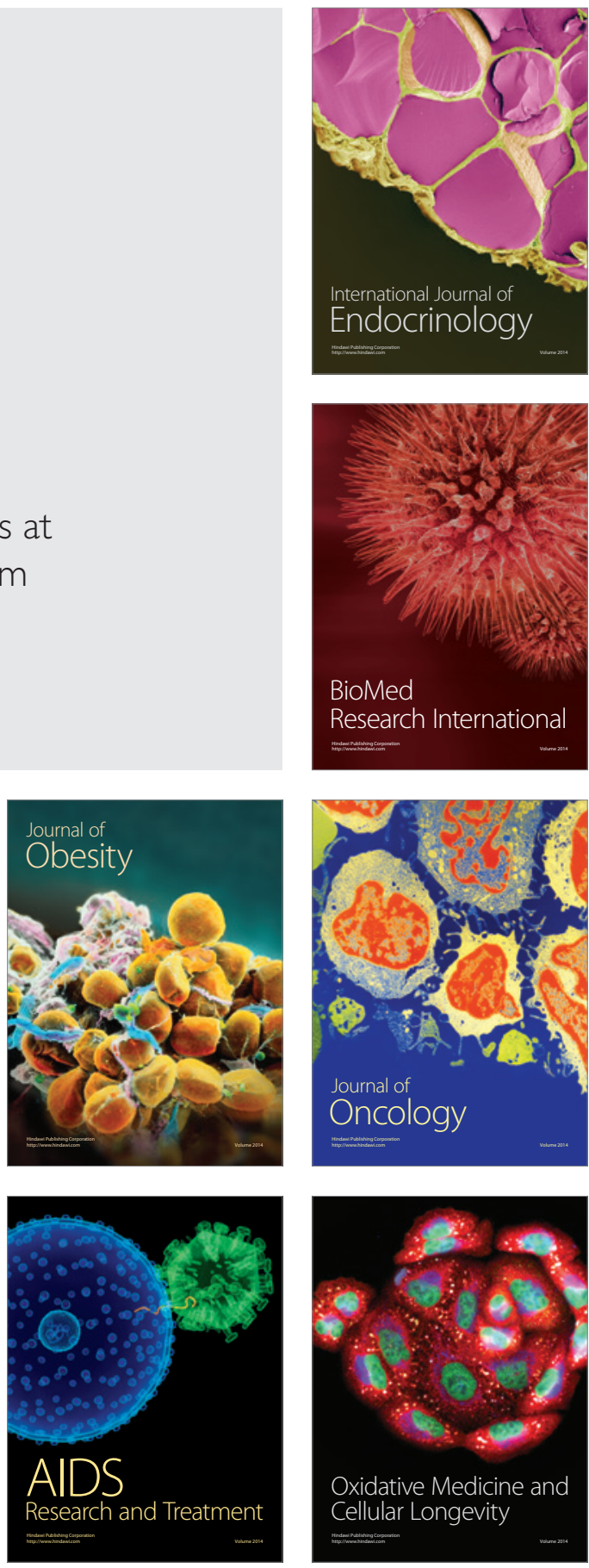